\title{
Bronchodilatation after inhalation of the antihistamine clemastine
}

\author{
S G NOGRADY, J P R HARTLEY, ${ }^{1}$ P D J HANDSLIP, AND N P HURST \\ From the Department of Tuberculosis and Chest Diseases, Welsh National School of Medicine, \\ Llandough Hospital, Nr Penarth, and the Asthma Research Unit, ${ }^{1}$ Sully Hospital, Sully, \\ $S$ Glamorgan, UK
}

Nogrady, S G, Hartley, J P R, Handslip, P D J, and Hurst, N P (1978). Thorax, 33, 479-482 Bronchodilatation after inhalation of the antihistamine clemastine. $\mathrm{H}_{1}$ receptor blocking antihistamines administered by mouth have not found a clear place in the management of bronchial asthma. We investigated the possibility that higher concentrations of these drugs, administered directly to the bronchial tree, might produce bronchodilatation.

Twelve asthmatic patients inhaled aerosols generated from solutions of clemastine ( $0.05 \%)$, salbutamol $(0.5 \%)$, and placebo. Bronchodilatation was assessed by changes in the forced expiratory volume in one second $\left(\mathrm{FEV}_{1}\right)$ and peak expiratory flow rate (PEFR) over four hours.

Both clemastine and salbutamol caused significant bronchodilatation. The mean maximum percentage increases in $\mathrm{FEV}_{1}$ for clemastine and salbutamol were $21 \cdot 1 \%$ and $29 \cdot 2 \%$ respectively. The mean maximum percentage increases in PEFR were $31.2 \%$ and $35.2 \%$ respectively. There was no significant difference in the maximum bronchodilatation produced by the two drugs.

Clemastine, when administered by aerosol inhalation, appears to be an effective bronchodilator.

The role of histamine in the production of acute asthma is controversial. There is evidence that histamine is released in allergic reactions in the lung (Schild et al, 1951), and challenge studies have shown that the bronchi of asthmatics are more sensitive to histamine than those of nonasthmatics (Curry, 1947; Tiffenau, 1958; Townley et al, 1965). Oral antihistamine drugs have not found a place in treating asthma, however, and are widely thought to be ineffective (Lancet, 1955).

Assuming that histamine plays a role in asthma, the therapeutic failure of antihistamines could be due either to the failure to block the $\mathrm{H}_{2}$ receptor sites or to incomplete $\mathrm{H}_{1}$ receptor blockade caused by inadequate local concentrations of drugs. Indeed, higher doses of antihistamines, given by mouth or parenterally, have caused bronchodilatation (Popa, 1977), but central nervous system depression limits their use by this route.

We have attempted to assess whether the administration of an $\mathrm{H}_{1}$ receptor blocking antihistamine, clemastine, given directly to the bronchi as an aerosol, could cause therapeutically useful bronchodilatation.

\section{Patients}

Twelve patients (age range 29-70, mean 46) gave informed consent. All were in hospital having recovered from a severe exacerbation of bronchial asthma and were in a relatively stable clinical state. All had previously shown reversibility of airways obstruction by a greater than $15 \%$ increase in peak expiratory flow rate (PEFR) after inhaling salbutamol aerosol $200 \mu \mathrm{g}$. Six of the twelve patients were atopic by prick skin testing.

On three consecutive mornings each patient had baseline measurements of PEFR (the best of three recordings) using a Wright peak flow meter and forced expiratory volume in one second $\left(\mathrm{FEV}_{1}\right)$ using a dry wedge spirometer (Vitalograph). Each subject then inhaled from a Wright's nebuliser $1 \mathrm{ml}$ each of either clemastine $0.05 \%$ in saline, salbutamol $0.5 \%$, or physiological saline as 
placebo. Each drug was administered double blind and in a sequence determined by the extended latin square design. PEFR and FEV $_{1}$ were measured at $5,15,30,45,60,90,120,180$, and 240 minutes after the inhalation. Results were analysed using Students " $t$ " test for paired samples.

\section{Results}

\section{PEFR}

All patients experienced an increase in PEFR with clemastine and salbutamol (fig 1 and tables 1 and 2). The mean baseline PEFR was $282 \pm 1001 / \mathrm{min}$ with no significant difference between the three treatment days. After inhalation of salbutamol there was a mean maximum percentage increase over each baseline of $35.2 \%$ at 45 minutes. After clemastine inhalation there was a mean maximum increase of $31.2 \%$ at 60 minutes. There was no significant difference between the maximum changes obtained with the two drugs. The onset of bronchodilatation was slower with clemastine than with salbutamol, but while with the latter there was only a $12 \%$ increase in PEFR at 240 minutes, with clemastine it was maintained at $20.2 \%$. Salbutamol became significantly better than placebo $(P<0.05)$ after five minutes; clemastine took longer.

Table 1 Mean percentage change in PEFR ( $\pm S D)$

\begin{tabular}{|c|c|c|c|c|c|}
\hline Time & Salbutamol & $P<0.05$ & Placebo & $P<0.05$ & Clemastine \\
\hline $\begin{array}{r}5 \\
15 \\
30 \\
45 \\
60 \\
90 \\
120 \\
180 \\
240\end{array}$ & $\begin{array}{l}23 \cdot 3 \pm 27 \cdot 7 \\
29 \cdot 3 \pm 34 \cdot 0 \\
31 \cdot 4 \pm 32 \cdot 8 \\
35 \cdot 2 \pm 37 \cdot 3 \\
34 \cdot 1 \pm 35 \cdot 3 \\
34 \cdot 5 \pm 34 \cdot 5 \\
31 \cdot 8 \pm 32 \cdot 9 \\
23 \cdot 9 \pm 26 \cdot 8 \\
12 \cdot 0 \pm 18 \cdot 4\end{array}$ & $\begin{array}{l}* \\
* \\
* \\
* \\
* \\
* \\
* \\
*\end{array}$ & $\begin{array}{r}10 \cdot 0 \pm 20 \cdot 9 \\
9 \cdot 3 \pm 20 \cdot 4 \\
10 \cdot 6 \pm 21 \cdot 3 \\
13 \cdot 8 \pm 15 \cdot 4 \\
13 \cdot 7 \pm 18 \cdot 0 \\
13 \cdot 3 \pm 19 \cdot 6 \\
15 \cdot 0 \pm 15 \cdot 4 \\
14 \cdot 2 \pm 19 \cdot 3 \\
-1 \cdot 5 \pm 10 \cdot 0\end{array}$ & $\begin{array}{l}* \\
* \\
* \\
*\end{array}$ & $\begin{array}{l}16 \cdot 2 \pm 25 \cdot 5 \\
23 \cdot 6 \pm 27 \cdot 2 \\
23 \cdot 5 \pm 30 \cdot 0 \\
27 \cdot 5 \pm 33 \cdot 2 \\
31 \cdot 2 \pm 31 \cdot 6 \\
29 \cdot 2 \pm 33 \cdot 0 \\
27 \cdot 6 \pm 27 \cdot 4 \\
23 \cdot 5 \pm 15 \cdot 4 \\
20 \cdot 2 \pm 12 \cdot 8\end{array}$ \\
\hline
\end{tabular}

Table 2 Individual baseline and peak values of PEFR with salbutamol, clemastine, and placebo

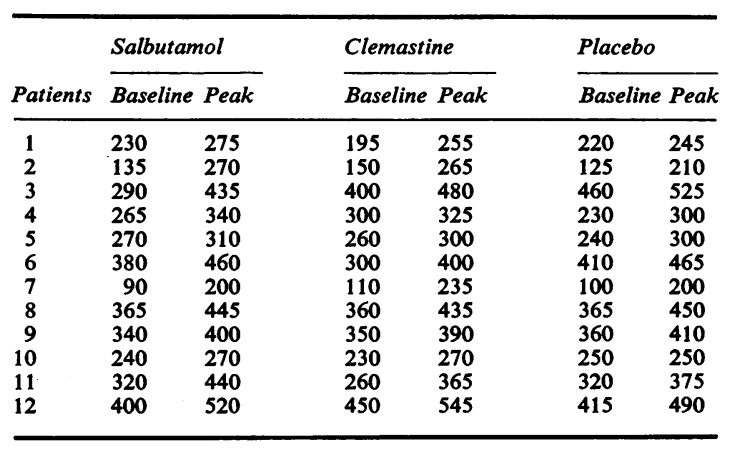

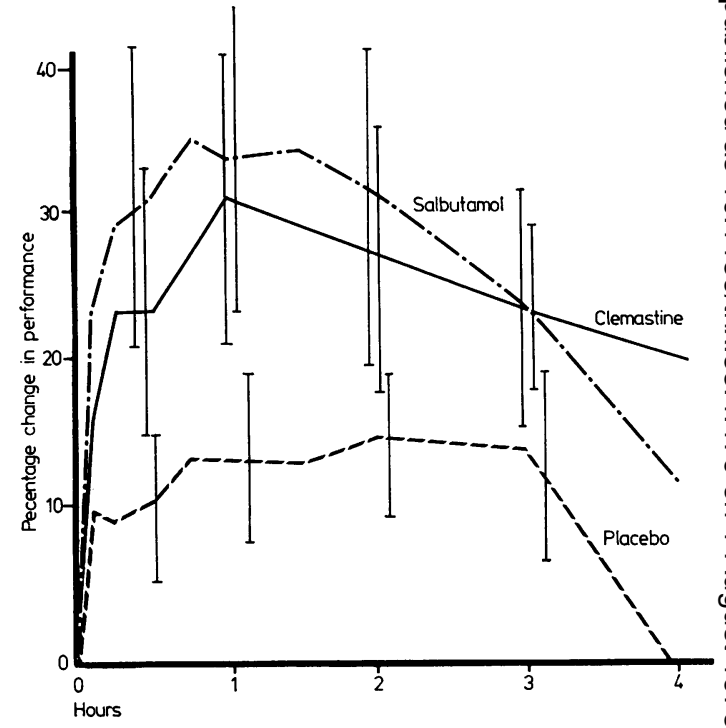

Fig 1 Percentage change $\pm S E$ in peak flow rate with inhaled salbutamol, clemastine, and placebo.

FEV $_{1}$

An increase in $\mathrm{FEV}_{1}$ was seen in all patients after $\stackrel{\circ}{\mathbb{D}}$ inhalation of clemastine and salbutamol (fig 2 and $\stackrel{2}{\overrightarrow{7}}$ tables 3 and 4 ). The mean baseline FEV $_{1}$ was $1.99 \pm 0.781$ with no significant difference between

Table 3 Mean percentage change in $F E V_{1}( \pm S D)$

\begin{tabular}{|c|c|c|c|c|c|}
\hline Time & Salbutamol & $P<0.05$ & Placebo & $P<0.05$ & Clemastine \\
\hline $\begin{array}{r}5 \\
15 \\
30 \\
45 \\
60 \\
90 \\
120 \\
180 \\
240\end{array}$ & $\begin{array}{c}19 \cdot 7 \pm 25 \cdot 0 \\
21 \cdot 2 \pm 23 \cdot 1 \\
27 \cdot 3 \pm 23 \cdot 3 \\
23 \cdot 2 \pm 24 \cdot 8 \\
26 \cdot 4 \pm 26 \cdot 5 \\
29 \cdot 2 \pm 26 \cdot 1 \\
20 \cdot 6 \pm 18 \cdot 2 \\
11 \cdot 8 \pm 19 \cdot 3 \\
4 \cdot 31 \pm 14 \cdot 8\end{array}$ & $\begin{array}{l}* \\
* \\
* \\
* \\
* \\
*\end{array}$ & $\begin{array}{c}4 \cdot 8 \pm 21 \cdot 2 \\
6 \cdot 6 \pm 21 \cdot 8 \\
8 \cdot 4 \pm 20 \cdot 7 \\
7 \cdot 3 \pm 16 \cdot 5 \\
7 \cdot 7 \pm 22 \cdot 5 \\
9 \cdot 1 \pm 20 \cdot 5 \\
13 \cdot 1 \pm 16 \cdot 2 \\
9 \cdot 8 \pm 21 \cdot 1 \\
0 \cdot 13 \pm 11 \cdot 4\end{array}$ & $\begin{array}{l}* \\
* \\
* \\
*\end{array}$ & $\begin{array}{c}9 \cdot 1 \pm 17 \cdot 3 \\
13 \cdot 3 \pm 22 \cdot 4 \\
18 \cdot 1 \pm 18 \cdot 7 \\
20 \cdot 4 \pm 21 \cdot 5 \\
21 \cdot 1 \pm 22 \cdot 3 \\
21 \cdot 1 \pm 20 \cdot 6 \\
17 \cdot 8 \pm 20 \cdot 2 \\
15 \cdot 2 \pm 17 \cdot 8 \\
10 \cdot 4 \pm 16 \cdot 4\end{array}$ \\
\hline
\end{tabular}

Table 4 Individual baseline and peak values of $F E V_{1}$ o with salbutamol, clemastine, and placebo

\begin{tabular}{|c|c|c|c|c|c|c|}
\hline \multirow[b]{2}{*}{ Patients } & \multicolumn{2}{|c|}{ Salbutamol } & \multicolumn{2}{|c|}{ Clemastine } & \multicolumn{2}{|l|}{ Placebo } \\
\hline & Baseline & Peak & Baseline & Peak & Baseline & Peak \\
\hline 1 & $1 \cdot 75$ & $1 \cdot 83$ & $1 \cdot 50$ & $1 \cdot 70$ & $1 \cdot 60$ & $1 \cdot 65$ \\
\hline 2 & $1 \cdot 10$ & 2.05 & $1 \cdot 20$ & $2 \cdot 00$ & 0.95 & $1 \cdot 60$ \\
\hline 3 & 2.65 & $3 \cdot 30$ & 3.85 & 3.85 & 3.80 & $4 \cdot 00$ \\
\hline 4 & $1 \cdot 50$ & 1.85 & $1 \cdot 60$ & 1.95 & $1 \cdot 25$ & 1.65 \\
\hline 5 & 2.45 & 2.95 & 2.45 & $2 \cdot 75$ & $2 \cdot 60$ & $2 \cdot 75$ \\
\hline 6 & $3 \cdot 50$ & $4 \cdot 15$ & $2 \cdot 50$ & $3 \cdot 50$ & $3 \cdot 30$ & $4 \cdot 00$ \\
\hline 7 & 0.75 & 1.45 & $1 \cdot 00$ & $1 \cdot 50$ & $1 \cdot 15$ & $1 \cdot 18$ \\
\hline 8 & $2 \cdot 55$ & 2.90 & $2 \cdot 60$ & $2 \cdot 80$ & $2 \cdot 40$ & $2 \cdot 75$ \\
\hline 9 & $2 \cdot 10$ & $2 \cdot 50$ & $2 \cdot 15$ & $2 \cdot 40$ & $2 \cdot 10$ & $2 \cdot 35$ \\
\hline 10 & 1.54 & $1 \cdot 68$ & 1.65 & 1.80 & $1 \cdot 48$ & 1.48 \\
\hline 11 & $1 \cdot 75$ & $2 \cdot 35$ & $1 \cdot 40$ & 1.90 & $1 \cdot 60$ & 1.90 \\
\hline 12 & 1.90 & $2 \cdot 60$ & $2 \cdot 20$ & 2.95 & $1 \cdot 83$ & $2 \cdot 36$ \\
\hline
\end{tabular}


the three treatment days. After salbutamol inhalation there was a mean maximum percentage increase over each baseline of $29 \cdot 2 \%$ at 90 minutes. With clemastine there was a mean maximum increase of $21.1 \%$ between 60 and 90 minutes. There was no significant difference between the maximum changes obtained with the two drugs. Salbutamol remained significantly better than placebo until 120 minutes. Clemastine remained significantly better than placebo until the end of the observation period at 240 minutes.

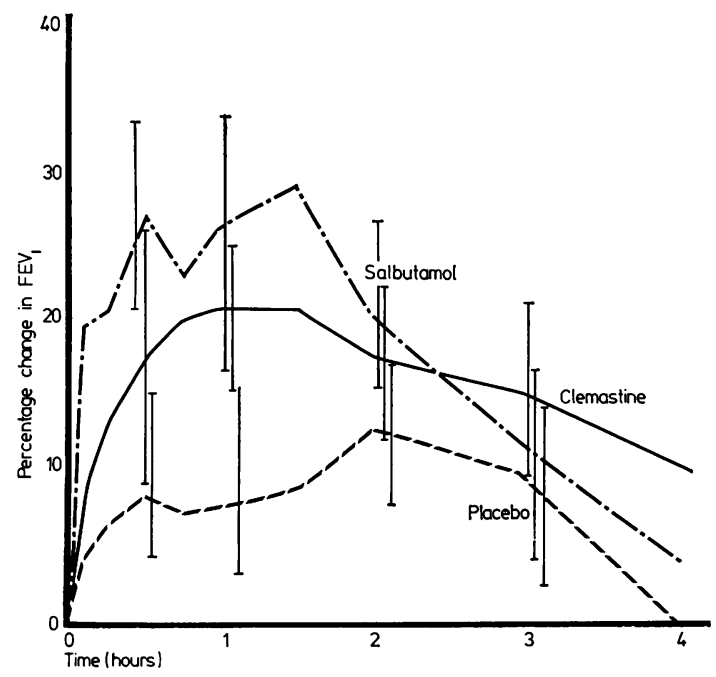

Fig 2 Percentage change $\pm S E$ in forced expiratory volume in 1 second with inhaled salbutamol, clemastine, and placebo.

\section{ATOPIC STATUS}

The mean maximum percentage increase in PEFR and $\mathrm{FEV}_{1}$ did not significantly differ between the atopic and non-atopic groups for either salbutamol or clemastine.

\section{SIDE EFFECTS}

No patient complained of any degree of irritation of the throat, nor of any other side effects.

\section{Discussion}

Histamine, along with other mediators of the allergic reaction, has been shown to be released from previous sensitised lung tissue on appropriate allergen challenge (Schild et al, 1951). Asthmatic patients show an increased bronchial reactivity to inhaled histamine (Curry, 1947; Townley et al, 1965 ), and this reactivity is more pronounced in symptomatic than in asymptomatic patients
(Cockcroft et al, 1977). Bhat et al (1976) showed a significant twofold rise in serum histamine concentration five minutes after allergen-induced bronchoconstriction, but not after methacholine-induced bronchoconstriction. Bruce et al (1976) found a higher plasma histamine concentration in subjects with acute severe asthma than in normal controls, though raised concentrations were also found in patients with other, less acute, chest illnesses.

In-vitro studies with the $\mathrm{H}_{1}$ receptor antagonist mepyramine, (Dunlop et al, 1977), have shown that complete receptor blockade in isolated bronchial muscle can cause relaxation, even in the presence of histamine. Mepyramine also significantly reduced the contraction of sensitised bronchial muscle in allergen challenge. Oral antihistamines have been recommended for treating asthma but have been found to be relatively ineffective and have failed to find a clear place in its management (Lancet, 1955). Herxheimer (1948 and 1949) showed that inhalation of mepyramine caused a slight increase in vital capacity in five asthmatic patients, and that inhalation of pyribenzamine and promethazine gave some protection against mild histamine, methacholine, and allergen-induced bronchoconstriction. Pyribenzamine aerosol also caused bronchodilatation in patients with spontaneous asthma. Feinberg et al (1948) showed that aerosols of several antihistamines could prevent histamine-induced bronchoconstriction in guinea pigs. Recent work has shown that inhaled diphenhydramine can prevent histamine-induced bronchoconstriction in asthmatic patients (Casterline and Evans, 1977). On the other hand, aerosols of antihistamines were found to be irritating, and in concentrations of greater than $2 \%$ could themselves cause bronchoconstriction in animals (Hawkins, 1955).

Clemastine is one of the benzhydrylether group of antihistamine compounds. It is a highly specific $\mathrm{H}_{1}$ receptor antagonist, and has no significant protective effect against bronchoconstriction induced by aerosols of acetylcholine or serotonin (Kallós, 1971). It causes little central nervous system depression as measured by critical flicker frequency depression (Hedges et al, 1971) and hand-eye co-ordination (Day et al, 1972). As an $\mathrm{H}_{1}$ receptor antagonist it is considerably more potent than promethazine and chlorpheniramine in preventing wheal formation after intradermal injection of histamine and histamine-induced bronchoconstriction in guinea pigs (Hedges et al, 1971). Our choice of a $0.05 \%$ solution was made after pilot studies, as the highest concentration that did not cause throat irritation with the 
delivery system used. At this concentration patients were aware of the characteristic taste, but it provoked neither complaints nor problems with cough or throat irritation. No side effects were observed during the study.

The finding that a specific $H_{1}$ receptor antagonist is an effective bronchodilator with a prolonged action raises again the question of the role of histamine in asthma. While it is possible that part of the bronchodilator effect may be due to anticholinergic properties, the specificity of the compound suggests otherwise. Further studies in histamine and methacholine-induced bronchoconstriction are in hand to resolve this question. Because the onset of bronchodilatation with inhaled clemastine is slower than with salbutamol, clemastine is likely to be of more use for the maintenance management of asthma than for the relief of acute attacks. Its use in conjunction with sympathomimetics and its role in the prevention of exercise-induced asthma are being investigated.

We would like to thank Mr G Berry of the MRC Pneumoconiosis Research Unit for statistical advice, Dr A Seaton for helpful criticism, and Mrs Pat Davies for preparing the manuscript.

\section{References}

Bhat, K N, Arroyave, C M, Marney, S R, Stevenson, D D, and Tan, E M (1976). Plasma histamine changes during provoked bronchospasm in asthmatic patients. Journal of Allergy and Clinical Immunology, 58, 647-656.

Bruce, C, Weatherstone, R, Seaton, A, and Taylor, W H (1976). Histamine levels in plasma, blood, and urine in severe asthma and the effect of corticosteroid treatment. Thorax, 31, 724-729.

Casterline, C L, and Evans, R (1977). Further studies on the mechanism of human histamine induced asthma. Journal of Allergy and Clinical Immunology, 59, 420-424.

Cockcroft, D W, Killian, D N, Mellon, J J A, and Hargreave, F E (1977). Bronchial reactivity to inhaled histamine: a method and clinical survey. Clinical Allergy, 7, 235-243.

Curry, J J (1947). Comparative action of acetyl-betamethylcholine and histamine on the respiratory tract in normals, patients with hay fever and sub- jects with bronchial asthma. Journal of Clinical Investigation, 26, 430-438.

Day, E S, Jones, S, Stewart-Jones, J, and Turner, P (1972). Clemastine on hand-eye co-ordination and visual function. Journal of Clinical Pharmacology, 12, 240.

Dunlop, L S, Smith, A P, and Piper, P J (1977). The effect of histamine antagonists on antigen-induced contractions of sensitised human bronchus in vitro. British Journal of Pharmacology, 59, 475.

Feinberg, S M, Noren, B, and Feinberg, R H (1948). Histamine antagonists. Journal of Allergy, 19, 9099.

Hawkins, D F (1955). Bronchoconstrictor and bronchodilator actions of antihistamine drugs. British Journal of Pharmacology, 10, 230-234.

Hedges, A, Hills, M, Maclay, W P, Newman-Taylor, 은 A J, and Turner, P (1971). Some central and peri- $\rightarrow$ pheral effects of Meclastine, a new antihistamine $?$ drug, in man. Journal of Clinical Pharmacology, 11, 112-119.

Herxheimer, H (1948). Aleudrine and Anthisan in bronchial spasm. Lancet, 1, 667-671.

Herxheimer, $H$ (1949). Antihistamines in bronchial 9 asthma. British Medical Journal, 2, 901-904.

Kallós, P (1971). Laboratory and clinical investigations of the antihistamine clemastine (Tavegyl). Clinical Trials Journal, 8, No 3, 23-26.

Lancet (1955), 2, 1182.

Popa, V T (1977). Bronchodilating activity of an $\mathbf{H}_{1}$ blocker, chlorpheniramine. Journal of Allergy and Clinical Immunology, 59, 54-63.

Schild, H O, Hawkins, D F, Mongar, J L, and Herxheimer, $H$ (1951). Reactions of isolated human asthmatic lung and bronchial tissue to specific antigen. Histamine release and muscular contractions. Lancet, 2, 376-383.

Tiffenau, R (1958). Cholinergic and histamine hypersensitivity of the lung of the asthmatic. Acta Allergoloqica, 12, suppl 5, 187-221.

Townley, R G, Dennis, M, and Itken, I H (1965). Comparative action of acetyl beta-methylcholine, histamine and pollen antigens in subjects with hay 응 fever and patients with bronchial asthma. Journal of Allergy, 31, 121-137.

Requests for reprints to: Dr S G Nogrady, Depart- $N$ ment of Tuberculosis and Chest Diseases, Welsh $\underset{\mathrm{W}}{\mathcal{N}}$ National School of Medicine, Llandough Hospital, Nr Penarth, S Glamorgan. 